\title{
Effect of Silver Nanowires on the Resistivity of Electroni- cally Conductive Adhesives
}

\author{
Xie Hui ${ }^{1}, \quad$ Xiong Nana $^{2}, \quad$ Zhao Yuzhen ${ }^{3}, \quad$ Wang Yuehui ${ }^{1}$ \\ ${ }^{1}$ University of Electronic Science and Technology of China, Zhongshan Institute, Zhongshan 528402, China; ${ }^{2}$ University of Electronic Science \\ and Technology, Chengdu 610054, China; ${ }^{3}$ Tsinghua University, Beijing 100084, China
}

\begin{abstract}
Large-scale silver nanowires with a length of 30 90 $\mu \mathrm{m}$ were synthesized by a polyol process. Electronically conductive adhesives (ECAs) were made by adding micro-sized silver flakes and silver nanowires to the polymer composites consisting mainly of epoxy resin, cure agent and catalyst. The volume resistivity of the ECAs was researched as a function of silver filling loading and sintering temperature. The results indicate that the volume resistivity of ECAs first decreases and then increases with the increase of fractions of silver nanowires when the curing temperature is $180{ }^{\circ} \mathrm{C}$. With the increase of curing temperature, the volume resistivity of ECAs decreases. In the condition of the ECAs filled with $65 \%$ silver fillers (the ratio of silver micro-sized silver flakes and silver nanowires is 55:10), the volume resistivity of ECAs reaches $6.5 \times 10^{-4}$ and $1.3 \times 10^{-4} \Omega \cdot \mathrm{cm}$ when cured at 180 and $300{ }^{\circ} \mathrm{C}$, respectively. The dramatic improvement in the conductivity of the ECAs is due to the low-temperature sintering of the silver nanowires at $300{ }^{\circ} \mathrm{C}$. Effect of silver nanowires on the resistivity of ECAs was discussed in terms of the distribution and sintering behavior of silver nanowires and interaction relationship between silver nanowires and micro-sized silver flakes.
\end{abstract}

Key words: electrical conductive adhesives; silver nanowires; volume resistivity; silver flakes

Recently, electrically conductive adhesives (ECAs) have become popular as one of promising candidates for lead-free interconnection solutions in microelectronic packaging application due to their technical advantages such as fewer processing steps, lower processing temperature, and fine pitch interconnect capability ${ }^{[1-5]}$. However, compared to the mature soldering technology, there are several limitations for conductive adhesives, such as relatively lower conductivity and unstable contact resistance ${ }^{[3-6]}$.

It is expected that there are advanced ECAs with both high electrical conductance and good adhesive strength. One feasible approach to this problem is the incorporation of silver nanostructures to establishment of perfect conductive pathways under the low content of conductive fillers ${ }^{[2-13]}$. Among these silver nanostructures, silver nanoparticles and nanowires have been used as conductive fillers in ECAs ${ }^{[2-13]}$. According to the reports, Ag nanowires were shown to be able to provide isotropically conductive adhesives (ICAs) with similar conductivity as traditional Ag flakes at much lower filler loading, and thus provide ECAs with better mechanical performance. Adding $\mathrm{Ag}$ nanoparticles into ICAs filled with $\mathrm{Ag}$ flakes generally showed a negative effect on electrical conductivity. Jiang et al. ${ }^{[2]}$ reported an ultrahigh conductive polymer composite by incorporating silver flakes and surface functionalized silver nanoparticles into epoxy. At a filler loading of 80 wt $\%$, the resistivity of the composite was dramatically reduced to as low as $5 \times 10^{-6} \Omega \cdot \mathrm{cm}$ owing to the lowtemperature sintering of the silver nanoparticles. Wu et al. ${ }^{[10]}$ developed an epoxy-based ICA filled with $56 \mathrm{wt} \%$ silver nanowires, and the bulk resistivity of ICA filled with the Ag nanowires was significantly lower than that of the ICAs filled with $1 \mu \mathrm{m}$ or $100 \mathrm{~nm}$ silver particles.

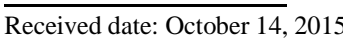

Foundation item: National Natural Science Foundation of China (61302044, 51302145); Natural Science Foundation of Guangdong Province (S2012010010646) Corresponding author: Wang Yuehui, Ph. D., Professor, Department of Chemistry and Biology, University of Electronic Science and Technology of China, Zhongshan Institute, Zhongshan 528402, P. R. China, Tel: 0086-760-88325742, E-mail: wangzsedu@126.com 
Consequently, to achieve the same level of electrical conductivity, the filler loading must be increased to at least $75 \mathrm{wt} \%$ for the ICA filled with micrometer-sized $\mathrm{Ag}$ particles.

In the present work, silver nanowires with a length of 30 $\sim 90 \mu \mathrm{m}$ were successfully synthesized by a polyol process. Further, the ICAs were made by adding micro-sized silver flakes and silver nanowires to the polymer composites consisting mainly of epoxy resin, cure agent and catalyst and their electrical properties were discussed.

\section{Experiment}

Silver nitrate $\left(\mathrm{AgNO}_{3}\right.$ purity $\left.\geq 99.8 \%\right)$ was purchased from Guangdong Guanghua Chemical Reagent Co., Ltd., poly (vinylprrolidone) (PVP, $\left.\mathrm{C}_{6} \mathrm{H}_{9} \mathrm{NO}\right) n, \mathrm{~K} 30, M \mathrm{w} \approx 40000$ ), was purchased from Guoyao Group Chemical Reagent Co., Ltd., while ferric chloride $\left(\mathrm{FeCl}_{3} \cdot 6 \mathrm{H}_{2} \mathrm{O}\right.$ purity $\left.\geq 99.0 \%\right)$, ethylene glycol $\left(\mathrm{EG},\left(\mathrm{HOCH}_{2}\right)_{2}\right.$ purity $\left.\geq 99.7 \%\right)$ and ethanol absolute $\left(\mathrm{CH}_{3} \mathrm{CH}_{2} \mathrm{OH}\right.$ purity $\left.\geq 99.7 \%\right)$ were purchased from Tianjin Yongda chemical Co., Ltd. Diglycidyl ether of bisphenol A (R-128) was purchased from Guangzhou Hongchang Co., Ltd. 4-methylhexahydrophthalic anhydride (MHHPA) and 2-ethyl-4-methylimidazole (2E4MZ) were supplied by Guangtuo Chemical Co., Ltd. Micro-sized silver flakes (SF1023K, $<5 \mu \mathrm{m}$ ) were purchased from Guangdong Fenghua Advanced Technology Group Co., Ltd. Silver nanowires were synthesized in our laboratory. All the chemicals were used as received.

The synthesis of silver nanowires in detail is as follows: $40 \mathrm{~mL}$ EG solution of $0.1 \mathrm{mmol} \cdot \mathrm{L}^{-1} \mathrm{Na}_{2} \mathrm{~S}$ was vigorously stirred after the addition of $0.16 \mathrm{~mol} \cdot \mathrm{L}^{-1}$ PVP. $40 \mathrm{~mL}$ $\mathrm{AgNO}_{3}\left(0.1 \mathrm{~mol} \cdot \mathrm{L}^{-1}\right)$ was injected drop by drop using a syringe into the above mixed solution in $1 \mathrm{~min}$, and stirred for $15 \mathrm{~min}$. Afterwards, the solution was put into a $100 \mathrm{~mL}$ Teflon-lined autoclave tube. This tube was sealed and maintained at $160{ }^{\circ} \mathrm{C}$ for $2.5 \mathrm{~h}$, followed by natural cooling to room temperature. Silver nanowires were easily purified by centrifuging at $5000 \mathrm{r} / \mathrm{min}$ for $15 \mathrm{~min}$ in the presence of acetone. These purified silver nanowires were redispersed in ethanol and added to the polymer matrix.

The ECAs were prepared based on the following procedure: $\mathrm{R}-128$, MHHPA and $2 \mathrm{E} 4 \mathrm{MZ}$ with a mass ratio of 1:0.85:0.04 were put in a small beaker, and sonicated for 30 min. Then, the silver nanowires were incorporated into the polymer matrix with sonication for another $30 \mathrm{~min}$ to make the fillers uniformly dispersed in the matrix. Two strips of polyimide tape were applied onto a pre-cleaned glass slide with a gap width of $1 \mathrm{~cm}$. The formulated composite was bladed into the space between the two strips. The polyimide tapes were removed before curing at the desired temperature and time. The thickness of the cured film was controlled by the polyimide tapes.

All scanning electron microscopy (SEM) images were taken on a MERLIN VP COMPACT (JSM-6460). The phase structures were determined by X-ray diffraction (XRD) (Rigaku2500 X-Ray DIFFRRACTOMETER) on a scintage diffractometer with $\mathrm{Cu} K \alpha(\lambda=0.154060 \mathrm{~nm})$ at a scanning rate of $2 \% \mathrm{~min}$ in the $2 \theta$ range from $20^{\circ}$ to $90^{\circ}$. The resistivity of the ICAs was measured using a DMR-1C four-point probe meter (Nanjing Daming instrument Co., LTD). The resistivity, $\rho$, was calculated using $\operatorname{Eq}(1)$ :

$$
\rho=R_{\mathrm{L}} \omega
$$

where, $R_{\mathrm{L}}$ and $\omega$ are square resistance and thickness of sample, respectively. The thickness of samples was measured by the micrometer gauge.

\section{Results and Discussion}

Fig.1 shows the SEM image and XRD pattern of the synthesized silver nanowires. We can seen from Fig.1a, there are a large amount of silver nanowires with a length of 30 90 $\mu \mathrm{m}$. 5 diffraction peaks can be observed in Fig.1b and indexed to the (111), (200), (220), (311) and (222) planes of pure face-centered-cubic (fcc) silver crystals. The lattice constants calculated from these XRD patterns is $0.40867 \mathrm{~nm}$, which are close to the reported data ( $a=$ $0.40862 \mathrm{~nm}$, JCPDS file 04-0783).

In order to study the sintering behavior, silver nanowires were sintered on a glass slide for $30 \mathrm{~min}$ at 180, 200, 250 and $300{ }^{\circ} \mathrm{C}$. Fig. 2 shows SEM images of the silver nanowires sintered on glass substrates at different temperatures for $30 \mathrm{~min}$. The sintering behavior of the silver nanowires is observed at $200{ }^{\circ} \mathrm{C}$, as shown in Fig. $2 \mathrm{~b}$. At $250{ }^{\circ} \mathrm{C}$, silver nanowires are obviously sintered and reshaped and fused to large chunks (Fig.2c). At $300{ }^{\circ} \mathrm{C}$, the silver nanowires form large chunks and connect with

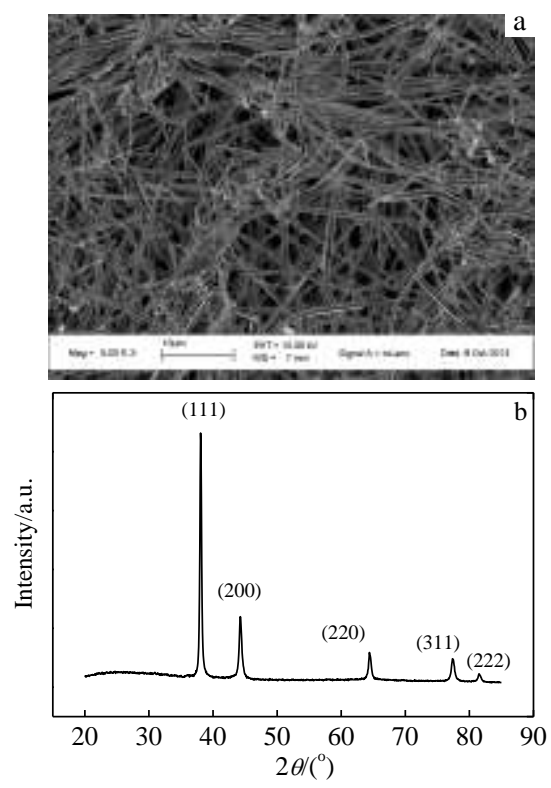

Fig.1 SEM image (a) and XRD pattern (b) of silver nanowires 


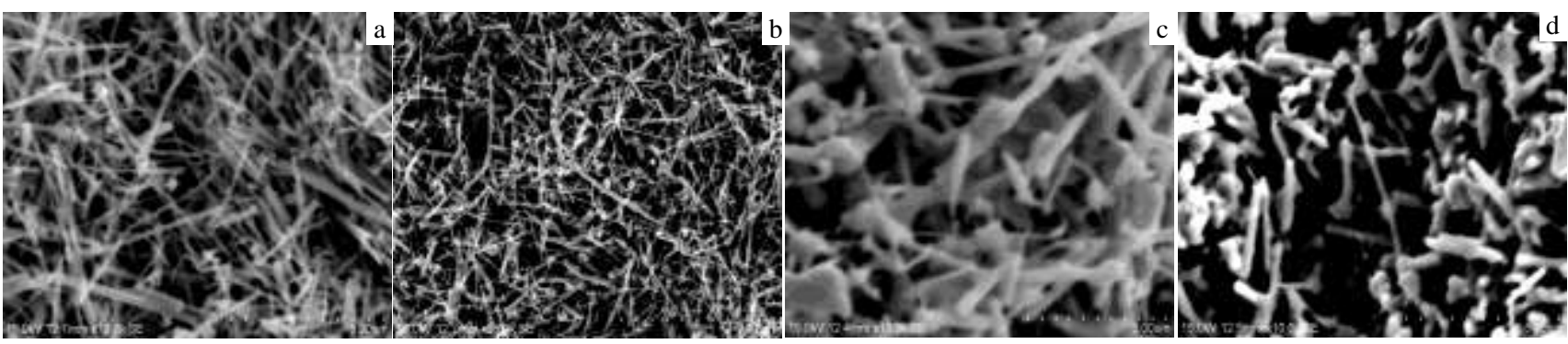

Fig.2 SEM images of the silver nanowires sintered at different temperatures: (a) $150{ }^{\circ} \mathrm{C}$, (b) $200{ }^{\circ} \mathrm{C}$, (c) $250{ }^{\circ} \mathrm{C}$, and (d) $300{ }^{\circ} \mathrm{C}$

each other, consisting of porous network. The porous microstructure may be explained by that the microstructure develops by grain boundary diffusion such as solid phase sintering or shape accommodation ${ }^{[2,10]}$.

Fig.3 shows the variations in electrical resistivity of ECAs filled with micro-sized silver flakes and different fractions of silver nanowires of the total silver fillers cured at $180{ }^{\circ} \mathrm{C}$ for $60 \mathrm{~min}$. The total silver fillers is $55 \mathrm{wt} \%$ and $65 \mathrm{wt} \%$. It is clear that the volume resistivity of both of ECAs first decreases and then increases with the increase of fraction of silver nanowires of the total silver fillers. The optimal fraction of silver nanowires of the total fillers is $20 \%$. In the condition of the ECAs filled with $55 \mathrm{wt} \%$ silver fillers, the volume resistivity of ECAs increases from 1.68 $\times 10^{-2} \Omega \cdot \mathrm{cm}$ to $5.39 \times 10^{-2} \Omega \cdot \mathrm{cm}$ when $40 \%$ silver nanowires of the total of fillers are added into polymer matrix. However, in the condition of the ECAs filled with $65 \mathrm{wt} \%$ silver fillers, the volume resistivity of ECAs increases from $2.70 \times 10^{-4} \Omega \cdot \mathrm{cm}$ to $9.42 \times 10^{-4} \Omega \cdot \mathrm{cm}$ when $40 \%$ silver nanowires of the total fillers are added into polymer matrix. This phenomenon indicates that silver nanowires can improve the electrical conductivity of ECAs in the condition of the proper fraction due to the larger contact area, fewer contact points and more stable contact.

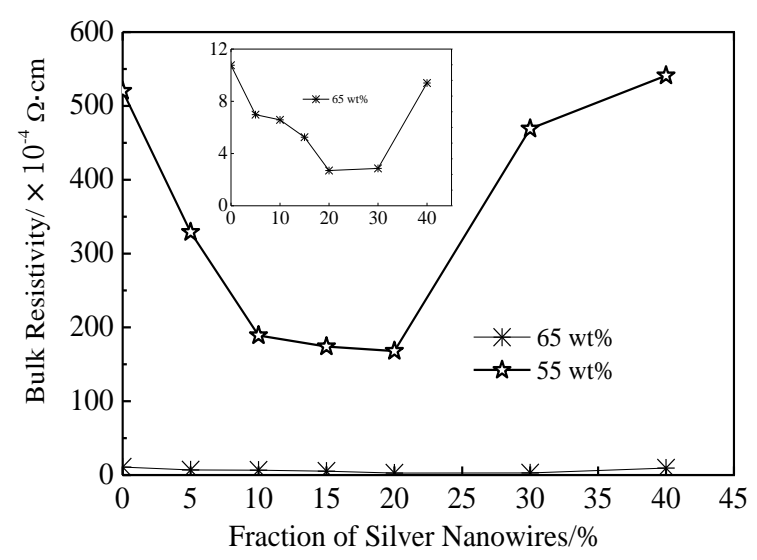

Fig.3 Variations in electrical resistivity of ECAs filled with micro-sized silver flakes and different fractions of silver nanowires of the total silver fillers cured at $180{ }^{\circ} \mathrm{C}$ for 60 $\min$
Fig.4 shows SEM images of the ECAs filled with micro-sized silver flakes and different fractions of silver nanowires of the total silver fillers cured at $180{ }^{\circ} \mathrm{C}$ for 60 min. Fig. $4 a_{1}, 4 b_{1}$ and $4 c_{1}$ is $0 \%, 10 \%, 30 \%$ silver nanowires in $55 \mathrm{wt} \%$ silver fillers, respectively. Fig. $4 \mathrm{a}_{2}, 4 \mathrm{~b}_{2}$ and $4 \mathrm{c}_{2}$ is $0 \%, 10 \%, 30 \%$ silver nanowires in $65 \mathrm{wt} \%$ silver fillers, respectively. Compared with the ECAs filled without silver nanowires, it is apparent that the nanowires span over the gap between two flake silver flakes and form a conductive pathway (Fig. $4 b_{1}, 4 b_{2}, 4 c_{1}$ and $4 c_{2}$ ). However, the adsorption of silver nanowires on the surface of silver flakes is observed when $30 \%$ silver nanowires of the total silver fillers are added into polymer matrix.

The electrical properties of ECAs primarily depend on the volume fraction, size, shape, and surface treatments of the filler particles and the curing state of the adhesive binder ${ }^{[1-7]}$. The electrical conductivity is achieved by contact between the filler particles. The electrical resistance is divided into intraparticle and interparticle resistances. The interparticle conduction is expected to be mainly governed by percolation, tunneling and constriction mechanisms ${ }^{[5-14]}$. Silver nanowires with high lengthdiameter ratio could reduce intraparticle resistance, and the tunnel resistance caused by the tunnel effect has little influence of ECAs filled with silver flakes and nanowires, so the increase of resistance is mainly associated with contact resistance in the system. Some of the work in the literature detailed the effect of silver nanowires on electrical properties of ECAs, and indicated silver nanowires could span over the gap between two flake silver particles and form a conductive pathway, therefore the number of conductive pathways could be increased and the effective contact area could be larger ${ }^{[2,6,14]}$. We had a similar conclusion in the case of the proper silver nanowires fraction of the total silver fillers. Compared with silver nanowires, silver flakes are much easier to form conductive networks ${ }^{[14]}$. In fact, the electrical conductivity of ECAs filled with silver flakes and nanowires depends on the conductive networks established by silver flakes and nanowires. A certain amount of silver nanowires mainly supply junctions for silver flakes-build networks; therefore the total number of conductive pathways increases in the 


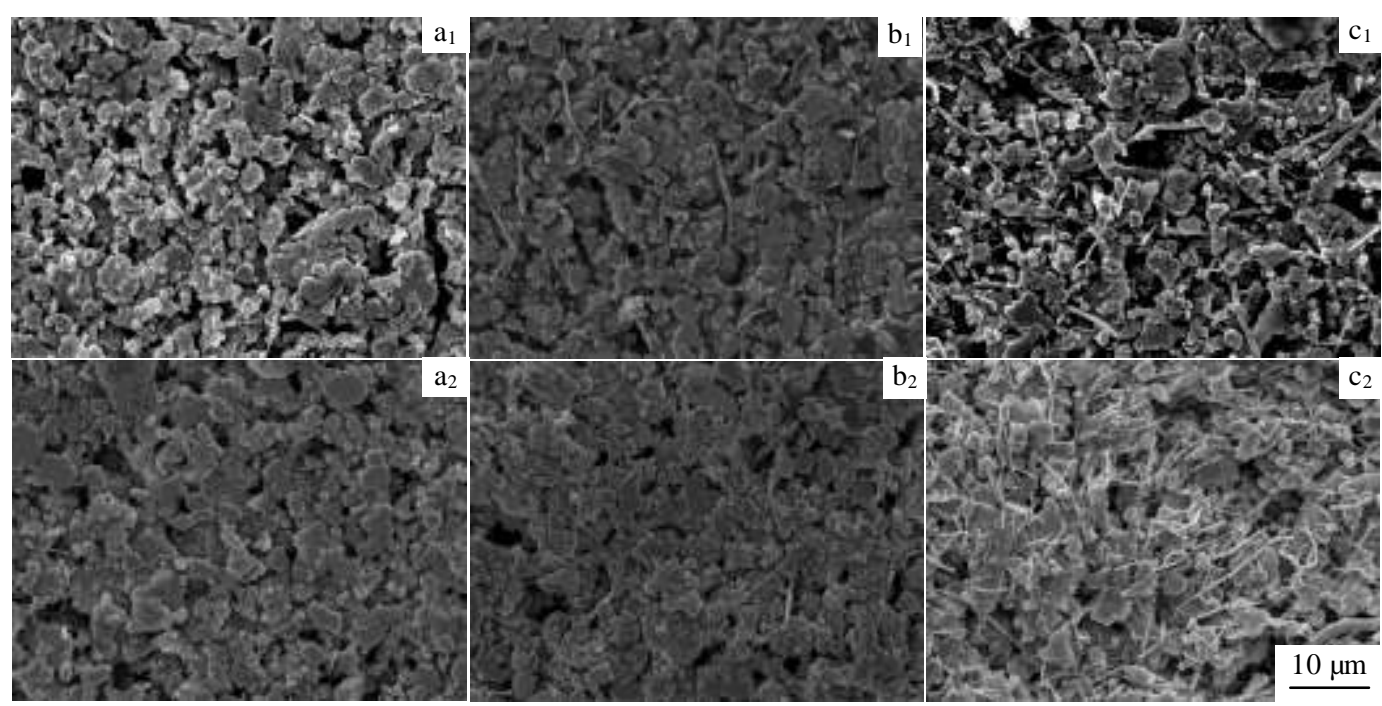

Fig.4 SEM images of the ECAs filled with micro-sized silver flakes and different fractions of silver nanowires of the total of silver fillers cured at $180^{\circ} \mathrm{C}$ for $60 \mathrm{~min}: \mathrm{a}_{1}, \mathrm{~b}_{1}$ and $\mathrm{c}_{1}$ is $0 \%, 10 \%, 30 \%$ silver nanowires in $55 \mathrm{wt} \%$ silver fillers, respectively; $\mathrm{a}_{2}, \mathrm{~b}_{2}$ and $\mathrm{c}_{2}$ is $0 \%$, $10 \%, 30 \%$ silver nanowires in $65 \mathrm{wt} \%$ silver fillers, respectively

system although the amount of silver flakes deceases. However, when the amount of silver nanoparticles of the total silver fillers exceeds $20 \%$ (in our experimental system), not only the conductive networks established by silver flakes obviously decrease but also silver nanowires agglomerate and adsorb on the surface of silver flakes that increase the contact resistance, so the electrical conductivity is damaged. The experimental results indicate that the improvement of the electrical conductivity of ECAS depends on the synergy of silver flakes and nanowires. It means that the silver nanowires mixed in the silver flakes only play a limited and auxiliary role in forming conductive networks.

Fig.5 shows the resistivity of the ECAs filled with micro-sized silver flakes and different fractions of silver nanoparticles of $65 \mathrm{wt} \%$ silver fillers cured at 180, 200, 250 and $300{ }^{\circ} \mathrm{C}$ for $60 \mathrm{~min}$. We can see from Fig.5 that with increasing of the curing temperature, the resistivity of all of ECAs decreases. The dependence of the electrical resistivities on the curing temperature suggests that there are some differences in the states of the percolation networks consisting of filler particles that also depend on the curing temperature. The conducting contacts between the filler particles are believed to be enhanced with increasing curing temperature due to the internal stress generated by shrinkage of the adhesive binder.

In the condition of the ECAs filled with $10 \%$ silver nanowires of $65 \mathrm{wt} \%$ silver fillers, the volume resistivity of ECAs reaches $6.5 \times 10^{-4}$ and $1.3 \times 10^{-4} \Omega \cdot \mathrm{cm}$ cured at 180 and $300{ }^{\circ} \mathrm{C}$, respectively. It is interesting to note that the resistivity of the ECAs first decreases and then increases

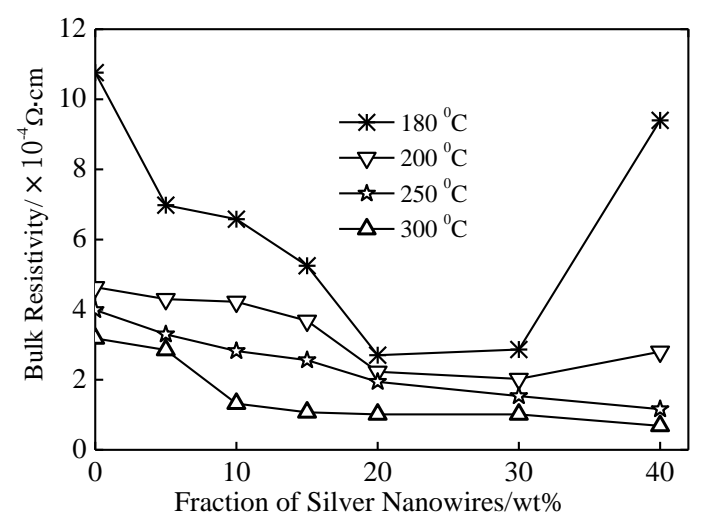

Fig.5 Variations in electrical resistivity of ECAs with microsized silver flakes and different fractions of silver nanoparticles of $65 \mathrm{wt} \%$ silver fillers cured at different temperatures for $60 \mathrm{~min}$

with increasing the silver nanowires fraction cured at 180 and $200{ }^{\circ} \mathrm{C}$, and it gradually decreases with the increase of silver nanowires fraction cured at $250{ }^{\circ} \mathrm{C}$. How it has little change cured at $300{ }^{\circ} \mathrm{C}$ when the fraction of silver nanowires is over $10 \%$.

The above results suggest that the effect of the curing temperature on the electrical conductivity is related to the fraction of silver nanowires of the total silver fillers. It is mainly because that the silver nanowires are sintered and fused to connect with each other to build the conductive network cured at $300{ }^{\circ} \mathrm{C}$, so a small amount of silver nanowires can fill well the gaps between silver flakes to realize the effective connection between silver fillers. In 

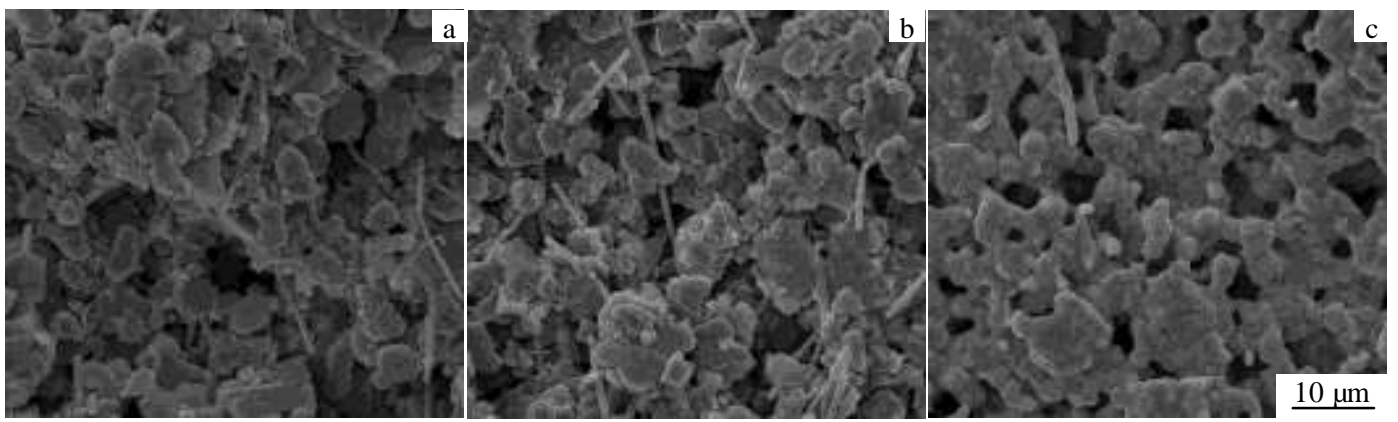

Fig.6 SEM images of the ECAs filled with micro-sized silver flakes and $10 \%$ silver nanoparticles of 65 wt $\%$ silver fillers cured at $200{ }^{\circ} \mathrm{C}(\mathrm{a}), 250{ }^{\circ} \mathrm{C}(\mathrm{b})$, and $300{ }^{\circ} \mathrm{C}(\mathrm{c})$

addition, we can see, that the curing temperature at $300{ }^{\circ} \mathrm{C}$ has a little effect on the electrical conductivity when the fraction of silver nanowires of the total silver filler is $20 \%$. It could be attributed to that the effective conductive pathways have been built after incorporated $20 \%$ silver nanowires in the system so the role of the connection among nanowires and silver flakes by sintering is not important. Based on the above results, we think the effective dispersion of fillers in the polymer matrix to establish more conductive paths is the key factor to obtain the high electrical conductivity.

Fig.6 shows SEM images of the ECAs filled with micro-sized silver flakes and $10 \%$ silver nanoparticles of 65 wt $\%$ silver fillers cured at 200, 250 and $300{ }^{\circ} \mathrm{C}$. Compared with Fig.2, the sintered behavior of silver nanowires is not observed cured at $200{ }^{\circ} \mathrm{C}$ (Fig.6a), indicating the epoxy resin covered on the surface of nanowires may prohibit sintering of silver nanowires. The extent of sintering of silver nanowires increases with increasing the temperature. Cured at $300{ }^{\circ} \mathrm{C}$, sintering of the silver nanowires and silver flake does exist in the epoxy composite which can be seen in Fig.6c, and form clumps with porous network, and they do reduce the contact resistance. In addition, in the higher curing temperature condition, the organic components, such as MHHPA and 2E4MZ, evaporate before the reaction with the epoxy, so they increase the silver content in ECAs, and thus improve the conductivity of ECAs. The sintered silver nanowires and silver flakes fuse to large chunks and form conductive network when cured at $300{ }^{\circ} \mathrm{C}$. In this case, the increase of silver nanowires does not improve the conductivity because the gaps between silver flakes could be filled well by sintered silver nanowires in the condition of $10 \%$ fraction.

\section{Conclusions}

1) Large-scale silver nanowires with a length of 30 90 $\mu \mathrm{m}$ are synthesized by a polyol process. ECAs are made by adding micro-sized silver flakes and silver nanowires to the polymer composites consisting mainly of epoxy resin, cure agent and catalyst.

2) The volume resistivity of ECAs first decreases and then increases with the increase of the fraction of the total silver nanowires of silver fillers cured at $180{ }^{\circ} \mathrm{C}$. With the increase of curing temperature, the volume resistivity of ECAs decreases.

3) The effect of the curing temperature on the electrical conductivity is related to the fraction of silver nanowires of the total silver fillers. The optimal fraction of silver nanoparticles of the total fillers is $20 \%$.

\section{References}

1 Lin Y C, Zhong J. J Mater Sci [J], 2008, 43: 3072

2 Jiang H, Moon K, Li Y et al. Chem Mater[J], 2006, 18(13): 2969

3 Chen D, Qiao X, Qiu X et al. Journal of Materials Science: Mater Electron[J], 2010, 21: 486

$4 \mathrm{Li} \mathrm{Y}$, Moon $\mathrm{K} \mathrm{S}$, Wong $\mathrm{C} \mathrm{P}$. IEEE Transctions on Components and Packaging Technologies[J], 2006, 29(1): 173

5 Cui H, Fan Q, Li D. Polym Int [J], 2013, 62: 1644

6 Zhang Z X, Chen X Y, Xiao F. Journal of Adhesion Science and Technology[J], 2011, 25: 1465

7 Yim B S, Kim J M. Mater Trans[J], 2010, 51(12): 2329

8 Lie X, Zheng B, Xu L et al. Rare Metal Materials and Engineering [J], 2012, 44(1): 24 (in Chinese)

9 Zhang R, Lin W, Moon K et al. Applied Materials and Interfaces $[\mathrm{J}], 2010,2(9): 2637$

$10 \mathrm{Wu} \mathrm{H}$ P, Liu J F, Wu X J et al. International Journal of Adhesion \& Adhesives[J], 2006, 26: 617

11 Yang C, Xie Y T, Yuen M et al. Advanced Functional Materials[J], 2010, 20: 2580

12 Ye L, Lai Z, Johan L et al. IEEE Transactions on Electronics Packaging Manufacturing[J], 1999, 22(4): 299

13 Qiao W Y, Bao H, Li X H S et al. International Journal of Adhesion \& Adhesives[J], 2014, 48: 159

14 Chen C, Wang L, Li R et al. J Mater Sci[J], 2007, 42: 3172 


\title{
纳米银线对导电胶电阻率影响
}

\author{
谢 辉 ${ }^{1}$, 熊娜娜 ${ }^{2}$, 赵玉珍 ${ }^{3}$, 王悦辉 ${ }^{1}$ \\ (1. 电子科技大学 中山学院, 广东 中山 528402) \\ (2. 电子科技大学, 四川成都 610054) \\ (3. 清华大学, 北京 10086)
}

\begin{abstract}
摘 要: 采用溶剂热法合成长30 90 $\mu \mathrm{m}$ 的纳米银线。以自制的纳米银线和商用微米银片为导电填料制备了环氧树脂基导电胶（ECAs）, 研究了纳米银含量和固化温度对导电胶电阻率的影响。结果表明, 当固化温度为 $180{ }^{\circ} \mathrm{C}$ 时, 随着纳米银含量的增加, 体积电阻率先下降 而后又增加; 随着固化温度的增加, 体积电阻率下降。当银粉总填质量分数为 $65 \%$ (微米银片和纳米银线的含量比是 $55: 10$ ) 时, 导电胶 在 180 和 $300{ }^{\circ} \mathrm{C}$ 固化的体积电阻率分别为 $6.5 \times 10^{-4}$ 和 $1.3 \times 10^{-4} \Omega \cdot \mathrm{cm}$ 。分析认为电阻率的下降与纳米银线在 $300{ }^{\circ} \mathrm{C}$ 出现烧结行为有关。根据纳 米银线在树脂基体中的分布、烧结行为和纳米银线与微米银片间的相互作用关系, 讨论了纳米银线对导电胶电阻率的影响机制。
\end{abstract} 关键词: 导电胶; 纳米银线; 体积电阻率; 银片粉

作者简介: 谢 辉, 男, 1976 年生, 博士, 电子科技大学中山学院化学与生物工程学院, 广东 中山 528402, 电话: 0769-88325742, E-mail: xiehuizsedu@126.com 